Fonseca, GKL, Araújo, CL \& Olivindo, DDF. (2020). Nursing entrepreneurship: motivations and possibilities for nursing entrepreneurs. Research, Society and Development, 9(7): 1-21, e597974442.

\title{
Empreendedorismo em Enfermagem: motivações e possibilidades para o enfermeiro empreender
}

Nursing entrepreneurship: motivations and possibilities for nursing entrepreneurs

Emprendimiento en Enfermería: motivaciones y posibilidades para empresarios de enfermería

Recebido: 12/05/2020 | Revisado: 14/05/2020 | Aceito: 19/05/2020 | Publicado: 30/05/2020

Grace Kelly Lima da Fonseca

ORCID: https://orcid.org/0000-0003-2101-5538

Centro Universitário Santo Agostinho, Brasil

E-mail: gracekelly.adm8@gmail.com

Clícia Lopes de Araújo

ORCID: https://orcid.org/0000-0002-3762-2511

Centro Universitário Santo Agostinho, Brasil

E-mail: cliciaraujom@gmail.com

Dean Douglas Ferreira de Olivindo

ORCID: https://orcid.org/0000-0002-9433-2625

Centro Universitário Santo Agostinho, Brasil

E-mail: dean_olivindo@yahoo.com.br

\section{Resumo}

Objetivo: Analisar na literatura o campo de atuação do enfermeiro no empreendedorismo em Enfermagem. Métodos: Trata-se de uma revisão bibliográfica da literatura, descritiva com abordagem qualitativa. A estratégia de busca foi realizada em março de 2020, por acesso de forma online das bases de dados: Publisher Medline (PUBMED), Scientific Electronic Library Online (SciELO), Literatura Latino-Americano e do Caribe em Ciências da Saúde (LILACS) e Bases de Dados de Enfermagem (BDENF). Utilizou-se os seguintes descritores em saúde: intrapreneurial, entrepreneurship, entrepreneurial, entrepreneurs, entrepreneurialism, iniciativa empresarial, Empresas e organizações de serviço, nursing, nurses e enfermagem. Foram incluídos na pesquisa: artigos completos disponíveis de forma 
livre e gratuita, idiomas português, inglês e espanhol. Excluídos artigos duplicados, teses e dissertações. Atingiu-se uma amostra de 16 estudos a serem analisados criteriosamente. Resultados: Para melhor assimilação dos dados, emergiram as seguintes categorias temáticas: Perfil do enfermeiro empreendedor; Motivos e aspirações que levam o enfermeiro ao empreendedorismo de negócios; Campo de atuação e variedade de negócios; Dificuldades e limitações ao empreendedorismo de negócios na Enfermagem; Empreendedorismo na formação acadêmica Considerações Finais: Conclui-se com esta pesquisa, que o empreendedorismo empresarial surge como uma inovadora área de atuação do enfermeiro no mercado de trabalho, possibilitando independência e autonomia profissional, além do desenvolvimento de concepções que estimulem os estudantes e profissionais da área de enfermagem a potencializar, aprimorar, e fortalecer ações empreendedoras como alternativa de crescimento profissional.

Palavras-chave: Autonomia profissional; Mercado de trabalho; Gestão em saúde; Serviços de Enfermagem.

\section{Abstract}

Goal: Analysis on literature the field action of nurses in the entrepreneurship nursing. Methods: It's about a bibliographical literature revision, written with an qualitative approach. The searching strategy was realized on March, 2020 through online database: Publisher Medline (PUBMED), Scientific Electronic Library Online (SciELO), Latin American and Caribbean Health Sciences Literature (LILACS) and Nursing Databases (BDENF). The following health descriptions were used: intrapreneurial, entrepreneurship, entrepreneurs, entrepreneurialism, entrepreneurship initiative, nursing and service organizations, nursing and nurses. They were included in search: fully articles available for free, Portuguese, English and Spanish idioms. They were excluded doubled articles, theses and dissertations. It was reached a sample of 15 studies to be judiciously analysed. Results: to get a better data approach they were emerged with the following thematic categories: Profile of entrepreneur nurse; Causes and aspirations that took out the nurse to business; entrepreneurship field of action and business variety; Difficulties and variations to nursing business entrepreneurship; entrepreneurship through the academic formation. Final Considerations: It is concluded that this search the business entrepreneurship looks like and innovative area of actuation to the nurse in business marketing being able to have itself professional independence beyond concept development to encourage students and health area professionals nurses to 
potencialize, improve and strengthen entrepreneur actions as an option of professional growing.

Key words: Professional autonomy; Job market; Health management; Nursing services.

\section{Resumen}

Objetivo: Analizar en la literatura el campo de acción de las enfermeras en emprendimiento en Enfermería. Métodos: Esta es una revisión de la literatura, descriptiva con un enfoque cualitativo. La estrategia de búsqueda se llevó a cabo en marzo de 2020, a través del acceso en línea a las bases de datos: Medline Publisher (PUBMED), Scientific Electronic Library Online (SciELO), Literatura Latinoamericana y del Caribe en Ciencias de la Salud (LILACS) y Bases de Datos de Enfermería (BDENF). Se utilizaron los siguientes descriptores de salud: intraemprendedores, emprendedores, emprendedores, emprendedores, emprendedurismo, iniciativa empresarial, empresas y organizaciones de servicios, enfermería, enfermeras y enfermería. La investigación incluyó: artículos completos disponibles de forma libre y gratuita, idiomas portugués, inglés y español. Artículos duplicados, tesis y disertaciones fueron excluidos. Se llegó a una muestra de 16 estudios para analizarlos cuidadosamente. Resultados: Para una mejor asimilación de los datos, surgieron las siguientes categorías temáticas: Perfil de la enfermera emprendedora; Razones y aspiraciones que llevan a las enfermeras al emprendimiento empresarial; Campo de actividad y variedad de negocios; Dificultades y limitaciones para el emprendimiento empresarial en enfermería; Emprendimiento en la formación académica Consideraciones finales: Se concluye con esta investigación, que el emprendimiento empresarial emerge como un área innovadora de trabajo de las enfermeras en el mercado laboral, lo que permite la independencia y la autonomía profesional, además del desarrollo de conceptos que alientan a los estudiantes y profesionales de la área de enfermería para mejorar, refinar y fortalecer las acciones empresariales como una alternativa para el crecimiento profesional.

Palabras clave: Autonomía profesional; Mercado de trabajo; Gestión en salud; Servicios de Enfermería.

\section{Introdução}

Ser empreendedor vai além de construir novas empresas, novos negócios ou revitalizar negócios já existentes, mas, ser a pessoa que promove mudanças e transformações, prevê, localiza e se beneficia com as oportunidades eventuais, incorporam inovações, estimulam o 
desenvolvimento econômico da região ou do país, realizam uma ideia ou projeto pessoal reputando riscos e responsabilidades. O espírito empreendedor está presente em todas as pessoas (Chiavenato, 2007), inclusive nos profissionais da Enfermagem.

A resolução do Conselho Federal de Enfermagem (COFEN) nº 0568/2018, regulamenta o funcionamento dos consultórios e clínicas de enfermagem, que oferecem serviços e/ou consultas de enfermagem, devendo estar adequadamente registrada como empresa nos Conselhos Regionais de Enfermagem, sendo isenta de pagamento de anuidades, porém, obriga o profissional a estar de acordo com sua situação financeira e cadastral. Sendo uma nova possibilidade de atuação do enfermeiro no mercado de trabalho (Cofen, 2018).

O mercado de trabalho brasileiro vivencia uma crise econômica e política, evidenciada pelo aumento do desemprego. Conforme a Pesquisa Perfil da Enfermagem no Brasil em 2016, de um contingente de 414.712 profissionais enfermeiros, 12,4\% dos enfermeiros referiram desemprego nos últimos 12 meses, e 78,9\% relataram dificuldade de encontrar emprego (Machado, 2016). A situação de estagnação e saturação do ramo de trabalho na enfermagem torna-se uma realidade a ser enfrentada e revertida. Em virtude disso, surgem as seguintes questões de pesquisa: Quais as possibilidades e oportunidades para o enfermeiro empreender? Que motivações conduziram os enfermeiros ao empreendedorismo empresarial?

O interesse pelo estudo manifestou-se mediante a vigente transformação na conjunção política e socioeconômica no Brasil, tais modificações resultam em impactos no mercado de trabalho, evidenciado pelas altas taxas de desemprego e baixos salários. Associado a essa problemática, encontra-se o profissional Enfermeiro, que enfrenta dificuldades referentes a própria profissão, como a sobrecarga de trabalho e a desvalorização profissional. Neste sentido, o empreendedorismo empresarial na enfermagem surge como uma alternativa inovadora, permitindo uma atuação autônoma e independente.

O presente estudo objetiva analisar na literatura o campo de atuação do enfermeiro no empreendedorismo, com isso, vislumbrando o fortalecimento da ampliação dos possíveis campos de emprego aos profissionais enfermeiros, conduzindo a novas possibilidades de atuação profissional, contribuindo para a formação de especialistas autônomos e independentes. 


\section{Metodologia}

Trata-se de um estudo descritivo, exploratório com abordagem qualitativa, na modalidade de revisão integrativa. Esta estratégia viabiliza uma análise ampliada da literatura, subsidiando uma percepção abrangente de um estipulado objeto de estudo, bem como ponderações sobre a execução de futuras pesquisas. Tal método possibilita sintetizar e elaborar conclusões sobre a compreensão produzida por pesquisas realizadas a respeito de determinado fenômeno. Podendo ser utilizado em inúmeros conteúdos e/ou fenômenos de estudo, colaborando para a prática de Enfermagem baseada em evidencias científicas (Whittemore \& Knafl, 2005; Mendes, Silveira \& Galvão, 2008).

Foi realizada uma busca criteriosa dos estudos selecionados nesta revisão, a seleção, análise e discussão foram feitas de forma rigorosa, sem plágios e conservando o pensamento original dos autores. Para a construção desta revisão integrativa, foram seguidas as consecutivas etapas: definição do problema e pergunta de pesquisa; coleta de dados após definição de critérios de inclusão e exclusão; caracterização dos estudos; análise e interpretação dos resultados coletados, detectando similaridades e conflitos; organização dos dados em categorias; e apresentação dos achados e considerações finais (Whittemore \& Knafl, 2005; Mendes et al., 2008).

Partindo do estabelecimento do problema, a questão norteadora da revisão de literatura foi: Quais as possibilidades e oportunidades para o enfermeiro empreender? Que motivações conduziram os enfermeiros ao empreendedorismo empresarial?

A estratégia de busca foi realizada em março de 2020, por acesso de forma online das bases de dados: Publisher Medline (PUBMED), Scientific Electronic Library Online (SciELO) e portal Bireme - Biblioteca Virtual em Saúde (BVS). A busca resultou em artigos das bases de dados Literatura Latino-Americano e do Caribe em Ciências da Saúde (LILACS) e Bases de Dados de Enfermagem (BDENF). Utilizaram-se os seguintes descritores em saúde: intrapreneurial, entrepreneurship, entrepreneurial, entrepreneurs, entrepreneurialism, iniciativa empresarial, Empresas e organizações de serviço, nursing, nurses e enfermagem.

Com o objetivo de proporcionar uma busca abrangente de estudos, os descritores controlados foram combinados de diversas maneiras, utilizando os operadores booleanos $O R$ e $A N D$ : Descritores em Ciência da Saúde (DeCs) para elaboração de estratégia de busca no 
portal BIREME; e no Medical Subject Headings (MeSH) para a PubMed. As estratégias de busca estão descritas abaixo (Quadro 1).

Quadro 1 - Estratégia de busca. Teresina, PI, Brasil, 2020.

\begin{tabular}{|c|c|}
\hline LILACS e BDENF & $\begin{array}{l}\text { (("Empresas e organizações de serviço" OR "entrepreneurship” OR } \\
\text { “empreendedorismo") AND (enfermagem OR nursing OR nurses)) } \\
\text { AND (collection:("06-national/BR" OR "05-specialized") AND } \\
\text { (fulltext:("1")) }\end{array}$ \\
\hline PUBMED & 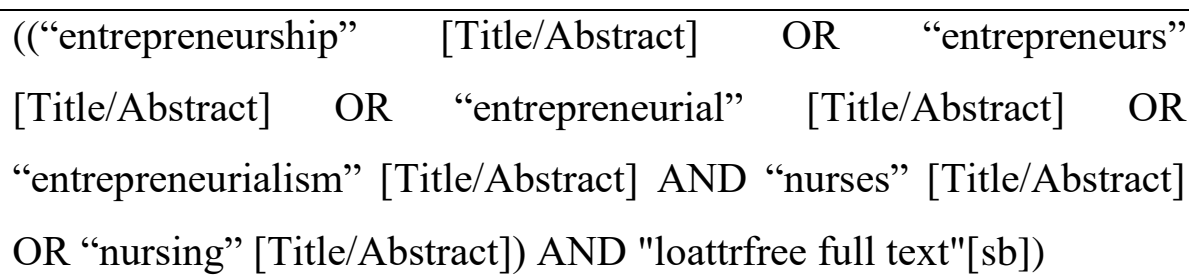 \\
\hline SCIELO & $\begin{array}{l}\text { (entrepreneurship) OR (entrepreneurs) OR (entrepreneurial) OR } \\
\text { (entrepreneurialism) OR (intrapreneurial ) OR ( "iniciativa } \\
\text { empresarial") OR (empreendedorismo) AND (enfermagem ) OR } \\
\text { (nursing) OR (nurses) OR (enfermeiros) AND in:* AND la:("pt" OR } \\
\text { "en") AND wok_subject_categories:("nursing") } \\
\text { type:("research-article") }\end{array}$ \\
\hline
\end{tabular}

Fonte: Dados da pesquisa, 2020.

A partir da coleta de dados, foram identificados 515 estudos. A primeira etapa da análise consistiu na aplicação dos critérios de inclusão e exclusão. Foram incluídos na pesquisa: artigos completos disponíveis de forma livre e gratuita, idiomas português, inglês e espanhol. Foram excluídos artigos duplicados, teses e dissertações. Com isso, obteve-se 86 artigos ao final da primeira etapa. Na segunda etapa, decorreu-se a leitura dos 86 estudos para detectar aqueles que respondiam adequadamente a pergunta norteadora da pesquisa e/ou tinham adequação com o fenômeno do estudo. A figura 1 ilustra o fluxograma das etapas. 
Figura 1 - Fluxograma da coleta, análise e seleção dos artigos. Teresina, PI, Brasil, 2020.

\begin{tabular}{|c|c|c|c|}
\hline \multicolumn{4}{|c|}{ ESTRATEGIA DE BUSCA } \\
\hline \multicolumn{4}{|c|}{ 几 } \\
\hline \multicolumn{4}{|c|}{ COLETA DE DADOS } \\
\hline \multicolumn{4}{|c|}{ TOTAL DE 515 ARTIGOS ENCONTRADOS } \\
\hline LILACS & BDENF & SCIELO & PUBMED \\
\hline \multirow[t]{2}{*}{29} & 22 & 280 & 184 \\
\hline & & \multicolumn{2}{|c|}{$\begin{array}{l}\text { Aplicado critérios de } \\
\text { inclusão e exclusão }\end{array}$} \\
\hline LILACS & BDENF & SCIELO & PUBMED \\
\hline \multirow[t]{2}{*}{29} & 22 & 11 & 24 \\
\hline & \multicolumn{3}{|c|}{$\begin{array}{l}\text { Quais as possibilidades e oportunidades } \\
\text { para o enfermeiro empreender? }\end{array}$} \\
\hline LILACS & BDENF & SCIELO & PUBMED \\
\hline 06 & 04 & 04 & 02 \\
\hline & & 6 ARTIGOS & \\
\hline
\end{tabular}

Fonte: Dados da pesquisa, 2020.

O fluxograma evidencia as etapas de coleta, análise e seleção dos artigos, resultando em uma amostra de 16 estudos inclusos na pesquisa, sendo 6 (37,5\%) da LILACS, 4 (25\%) da BDENF, 4 (25\%) da SciELO e 2 (12,5\%) da PUBMED. A análise e a interpretação dos dados foram organizadas por meio da visualização dos dados em um quadro, apresentado nos resultados da pesquisa (Quadro 2), estruturado nas seguintes colunas: título do estudo/autor, abordagem, ano de publicação e objetivos.

Para melhor assimilação dos dados, após ampla leitura dos textos completos e análise criteriosa dos resultados encontrados nos artigos, emergiram as seguintes categorias temáticas a serem abordadas: Perfil do enfermeiro empreendedor; Motivos e aspirações que levam o enfermeiro ao empreendedorismo de negócios; Campo de atuação e variedade de negócios; 
Dificuldades e limitações ao empreendedorismo de negócios na Enfermagem; Empreendedorismo na formação acadêmica.

\section{Resultados}

Ficou evidenciada a escassez de artigos sobre o tema. Entre os 16 estudos selecionados, observou-se que a maioria dos estudos se concentraram no ano de 2018, com 4 artigos (25\%), ano pelo qual foi instituída a resolução COFEN nº 0568/2018, que regulamenta o funcionamento dos consultórios e clínicas de enfermagem. Um (6,25\%) em 2009, 2015 e 2020, dois (12,5\%) em 2016, 2017 e 2019 e três (18,75\%) em 2013. Refletindo a contemporaneidade do tema e a necessidade emergente de visibilidade desta temática.

As características dos 16 estudos inclusos nesta revisão podem ser observados no Quadro 2. Para melhor assimilação dos dados, após ampla leitura dos textos completos e análise criteriosa dos resultados encontrados nos artigos, emergiram as seguintes categorias temáticas a serem abordadas: Perfil do enfermeiro empreendedor; Motivos e aspirações que levam o enfermeiro ao empreendedorismo de negócios; Campo de atuação e variedade de negócios; Dificuldades e limitações ao empreendedorismo de negócios na Enfermagem; Empreendedorismo na formação acadêmica (Quadro 3).

Quadro 2 - Características dos estudos segundo título, autor, abordagem, ano e objetivo. Teresina, PI, Brasil, 2020.

\begin{tabular}{|c|l|c|c|c|}
\hline $\mathbf{N}^{\circ}$ & TÍTULO/AUTOR & ABORDAGEM & ANO & \multicolumn{1}{|c|}{ OBJETIVO } \\
\hline $\mathbf{0 1}$ & $\begin{array}{l}\text { Características empreendedoras } \\
\text { de enfermeiras: um estudo no } \\
\text { sul do Brasil. } \\
\text { (Carvalho et al., 2016) }\end{array}$ & Quantitativo & 2016 & $\begin{array}{l}\text { Identificar as características } \\
\text { empreendedoras de enfermeiras. }\end{array}$ \\
\hline $\mathbf{0 2}$ & $\begin{array}{l}\text { Empreendedorismo na } \\
\text { enfermagem: comparação com } \\
\text { (Colichi \& Lima, 2018) }\end{array}$ & Quantitativo & 2018 & $\begin{array}{l}\text { Caracterizar as empresas de } \\
\text { enfermagem e outras profissões } \\
\text { da saúde, comparando indicadores } \\
\text { relacionados au } \\
\text { empreendedorismo entre essas } \\
\text { categorias profissionais. }\end{array}$ \\
\hline
\end{tabular}


Research, Society and Development, v. 9, n. 7, e597974442, 2020

(CC BY 4.0) | ISSN 2525-3409 | DOI: http://dx.doi.org/10.33448/rsd-v9i7.4442

\begin{tabular}{|c|c|c|c|c|}
\hline 03 & $\begin{array}{l}\text { Empreendedorismo de negócios } \\
\text { e Enfermagem: revisão } \\
\text { integrativa. } \\
\text { (Colichi et al, 2019) }\end{array}$ & $\begin{array}{l}\text { Revisão } \\
\text { integrativa }\end{array}$ & 2019 & $\begin{array}{l}\text { Identificar o conhecimento } \\
\text { produzido } \\
\text { empreendedorismo de negócios } \\
\text { na Enfermagem. }\end{array}$ \\
\hline 04 & $\begin{array}{l}\text { Arte e Ciência do Cuidar: } \\
\text { Alteridade, Estabelecidos e } \\
\text { Outsiders na Autonomia do } \\
\text { Enfermeiro como Profissional } \\
\text { Liberal. } \\
\text { (Silva et al, 2019) }\end{array}$ & Qualitativo & 2019 & $\begin{array}{l}\text { Compreender o processo de } \\
\text { construção da autonomia do } \\
\text { enfermeiro como profissional } \\
\text { liberal. }\end{array}$ \\
\hline 05 & $\begin{array}{l}\text { Estudantes de enfermagem têm } \\
\text { perfil empreendedor? } \\
\text { (Roncon \& Munhoz, 2009) }\end{array}$ & $\begin{array}{l}\text { Descritivo- } \\
\text { exploratória }\end{array}$ & 2009 & $\begin{array}{l}\text { Conhecer o perfil dos estudantes } \\
\text { concluintes de um curso de } \\
\text { graduação em enfermagem quanto } \\
\text { ao empreendedorismo. }\end{array}$ \\
\hline 06 & $\begin{array}{l}\text { Empreendedorismo na } \\
\text { Enfermagem: revisão } \\
\text { integrativa da literatura. } \\
\text { (Copelli, Erdmann \& Santos, } \\
\text { 2019) }\end{array}$ & $\begin{array}{c}\text { Revisão } \\
\text { integrativa. }\end{array}$ & 2019 & $\begin{array}{l}\text { Evidenciar na literatura nacional e } \\
\text { internacional o conceito e as } \\
\text { tipologias de empreendedorismo } \\
\text { na Enfermagem }\end{array}$ \\
\hline 07 & $\begin{array}{l}\text { O empreendedorismo de } \\
\text { negócios entre enfermeiros } \\
\text { (Chagas et al., 2018) }\end{array}$ & Quantitativo & 2018 & $\begin{array}{l}\text { Identificar o empreendedorismo } \\
\text { de negócios entre enfermeiros }\end{array}$ \\
\hline 08 & $\begin{array}{l}\text { Perfil empreendedor de } \\
\text { docentes do curso de } \\
\text { enfermagem de uma } \\
\text { universidade pública. } \\
\text { (Tossin et al., 2017) }\end{array}$ & Quantitativo & 2017 & $\begin{array}{l}\text { Verificar a tendência } \\
\text { empreendedora de docentes do } \\
\text { curso de enfermagem de uma } \\
\text { universidade estadual pública. }\end{array}$ \\
\hline 09 & $\begin{array}{l}\text { Empreendedorismo na } \\
\text { Enfermagem: panorama das } \\
\text { empresas no Estado de São } \\
\text { Paulo. } \\
\text { (Andrade et al., 2015) }\end{array}$ & $\begin{array}{c}\text { Estudo } \\
\text { exploratório }\end{array}$ & 2015 & $\begin{array}{llll}\text { Identificar } & \text { e } & \text { caracterizar as } \\
\text { empresas } & \text { de } & \text { enfermagem } \\
\text { dirigidas } & \text { por } & \text { enfermeiros } \\
\text { empresários, registradas na Junta } \\
\text { Comercial do } \\
\text { Paulo. }\end{array}$ \\
\hline 10 & Características empreendedoras & Qualitativo & 2013 & $\begin{array}{l}\text { Conhecer as características } \\
\text { empreendedoras do graduando em }\end{array}$ \\
\hline
\end{tabular}




\begin{tabular}{|c|c|c|c|c|}
\hline & $\begin{array}{l}\text { do futuro enfermeiro. } \\
\text { (Ferreira et al., 2013) }\end{array}$ & & & enfermagem. \\
\hline 11 & $\begin{array}{l}\text { Perfil empreendedor do } \\
\text { enfermeiro: contribuição da } \\
\text { formação acadêmica. } \\
\text { (Lima et al., 2019) }\end{array}$ & Qualitativo & 2019 & $\begin{array}{l}\text { Conhecer as contribuições da } \\
\text { formação do enfermeiro como } \\
\text { subsídio para o desenvolvimento } \\
\text { de uma atitude empreendedora na } \\
\text { perspectiva de enfermeiros } \\
\text { empresários. }\end{array}$ \\
\hline 12 & $\begin{array}{l}\text { Características psicológicas do } \\
\text { empreendedorismo dos } \\
\text { enfermeiros. } \\
\text { (Dehghanzadeh et al., 2016) }\end{array}$ & Quantitativa & 2016 & 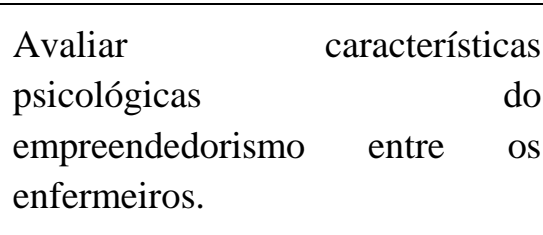 \\
\hline 13 & $\begin{array}{l}\text { A experiência das enfermeiras } \\
\text { empreendedoras iranianas em a } \\
\text { identificação de oportunidades } \\
\text { empresariais. } \\
\text { (Jahani et al., 2020) }\end{array}$ & Qualitativo & 2020 & $\begin{array}{l}\text { Descrever as experiências de } \\
\text { empresários iranianos na } \\
\text { identificação de oportunidades } \\
\text { adequadas em empreendedorismo. }\end{array}$ \\
\hline 14 & $\begin{array}{l}\text { Tendências empreendedoras } \\
\text { dos enfermeiros de um hospital } \\
\text { universitário. } \\
\text { (Costa et al., 2013) }\end{array}$ & Quantitativo & 2013 & $\begin{array}{l}\text { Identificar } \\
\text { empreendedoras dos enfermeiros } \\
\text { de um hospital universitário e } \\
\text { relacioná-las com idade, tempo de } \\
\text { trabalho e conclusão do curso de } \\
\text { enfermagem. }\end{array}$ \\
\hline 15 & $\begin{array}{l}\text { Práticas de enfermagem } \\
\text { empreendedoras e autônomas. } \\
\text { (Morais et al., 2013) }\end{array}$ & Quantitativo & 2013 & $\begin{array}{l}\text { Caracterizar as práticas de } \\
\text { enfermagem empreendedoras no } \\
\text { Estado do Paraná. }\end{array}$ \\
\hline 16 & $\begin{array}{l}\text { Empreendedorismo em } \\
\text { enfermagem: um caminho } \\
\text { promissor à luz da teoria de } \\
\text { horta. } \\
\text { (Araújo \& Nunes, 2018) }\end{array}$ & Qualitativo & 2018 & $\begin{array}{l}\text { Conhecer } \quad \text { experiências } \\
\text { empreendedoras na Enfermagem } \\
\text { à luz da Teoria de Horta. }\end{array}$ \\
\hline
\end{tabular}

Fonte: Pesquisa direta em Base de Dados, 2020.

Dos 16 artigos selecionados, o Quadro 2 mostra que todos os títulos e objetivos estão em concordância com os objetivos propostos na revisão, que busca analisar na literatura o campo de atuação do enfermeiro no empreendedorismo. Com relação a abordagem das 
pesquisas, observou-se a prevalência de pesquisas quantitativas $(43,75 \%)$ e qualitativas (31,25\%), seguidos das revisões (12,5\%) e estudos exploratórios $(12,5 \%)$.

Quadro 3 - Categorias Temáticas e frequência dos resultados nos artigos. Teresina, PI, Brasil, 2020.

\begin{tabular}{|c|c|c|c|}
\hline Categoria temática & Resultados & $\begin{array}{c}\text { Artigos } \\
\text { referentes }\end{array}$ & Frequência \\
\hline $\begin{array}{l}\text { Perfil do enfermeiro } \\
\text { empreendedor }\end{array}$ & $\begin{array}{l}\text { Destacou a prevalência do sexo feminino, } \\
\text { jovens, predominando a faixa etária entre } 27 \\
\text { a } 40 \text { anos com pouco tempo de trabalho. } \\
\text { Dispõe de senso de oportunidade, } \\
\text { independência, autonomia, inovação, } \\
\text { flexibilidade, comunicação, opera de forma } \\
\text { holística, domina cenários novos de atuação } \\
\text { direcionados ao cuidado, valoriza a profissão } \\
\text { perante a sociedade, comprometimento, } \\
\text { estabelecimento de metas; força de vontade, } \\
\text { competência, busca por conhecimento e } \\
\text { exploração do campo de trabalho. }\end{array}$ & $\begin{array}{l}01-03- \\
04-06- \\
07-08- \\
10-11- \\
12-14- \\
16\end{array}$ & $\begin{array}{c}\text { Abordado } \\
\text { em } 11 \text { artigos }\end{array}$ \\
\hline $\begin{array}{c}\text { Motivos e aspirações } \\
\text { que levam o } \\
\text { enfermeiro ao } \\
\text { empreendedorismo } \\
\text { de negócios }\end{array}$ & $\begin{array}{l}\text { Ambientes organizacionais estressores; } \\
\text { turnos e sobrecarga de trabalho; baixos } \\
\text { salários oferecidos à categoria nos serviços } \\
\text { privados; desgaste emocional por trabalhar } \\
\text { muito tempo como empregado; modelo } \\
\text { médico-centrado; desemprego; ausência de } \\
\text { autonomia; buscam flexibilidade nos horários } \\
\text { de trabalho; geração de renda; demanda de } \\
\text { pacientes; vislumbram possibilidade de } \\
\text { lucratividade, independência e autonomia; } \\
\text { estar no comando; ser seu próprio chefe; } \\
\text { possuir controle de carreira; ser bem } \\
\text { sucedido; busca pela satisfação profissional. }\end{array}$ & $\begin{array}{l}02-03- \\
04-07- \\
09-11- \\
13-15- \\
16\end{array}$ & $\begin{array}{c}\text { Abordado } \\
\text { em } 9 \text { artigos } \\
56,25 \%\end{array}$ \\
\hline $\begin{array}{l}\text { Campo de atuação e } \\
\text { variedade de } \\
\text { negócios }\end{array}$ & $\begin{array}{l}\text { Terapias alternativas; estética, como } \\
\text { depilação a laser e aplicação de cosméticos; } \\
\text { aluguel de equipamentos; fabricação de } \\
\text { produtos; podologia; atividades de assessoria, } \\
\text { consultoria e gestão de projetos; instituto de } \\
\text { repouso, moradia temporária e permanente } \\
\text { para idosos; clínica de assistência domiciliar; } \\
\text { educação; saúde ocupacional; transporte de } \\
\text { pacientes; pesquisa; serviços que ofertam }\end{array}$ & $\begin{array}{l}03-09- \\
11-13- \\
15\end{array}$ & $\begin{array}{c}\text { Abordado } \\
\text { em } 5 \text { artigos }\end{array}$ \\
\hline
\end{tabular}




\begin{tabular}{|c|c|c|c|}
\hline & $\begin{array}{l}\text { treinamentos, cursos preparatórios e de } \\
\text { aperfeiçoamento profissional; comercio e } \\
\text { marketing de produtos; cuidados de crianças } \\
\text { e adolescentes; desenvolvimento de software; } \\
\text { e clinicas privada. }\end{array}$ & & \\
\hline $\begin{array}{l}\text { Dificuldades e } \\
\text { limitações ao } \\
\text { empreendedorismo } \\
\text { de negócios na } \\
\text { Enfermagem }\end{array}$ & $\begin{array}{l}\text { Dificuldades financeiras, privação de preparo } \\
\text { na graduação para empreenderem, ausência } \\
\text { de conhecimentos de noções de } \\
\text { contabilidade, questões legais e regulatórias } \\
\text { que engloba carência de entendimento de } \\
\text { legislação e processos burocráticos para } \\
\text { licenciamento, gestão e registro de acordos } \\
\text { privados, concorrência desleal, vinculada a } \\
\text { escassez de credibilidade e insipiência da } \\
\text { população a respeito das possibilidades de } \\
\text { atuação do enfermeiro. }\end{array}$ & $\begin{array}{l}02-03- \\
04-07- \\
15\end{array}$ & $\begin{array}{l}\text { Abordado } \\
\text { em } 5 \text { artigos } \\
31,25 \%\end{array}$ \\
\hline $\begin{array}{c}\text { Empreendedorismo } \\
\text { na formação } \\
\text { acadêmica. }\end{array}$ & $\begin{array}{l}\text { Ausência de disciplina de empreendedorismo } \\
\text { e incentivo no decorrer da graduação para } \\
\text { desenvolvimento da prática de empreender. } \\
\text { O empreendedorismo precisa ser estimulado } \\
\text { na formação acadêmica devido a sua } \\
\text { significativa influência no crescimento } \\
\text { econômico e social do país e da própria } \\
\text { profissão de enfermagem. }\end{array}$ & $\begin{array}{l}\text { Abordado } \\
\text { nos } 16 \\
\text { artigos }\end{array}$ & $\begin{array}{l}\text { Abordado } \\
\text { nos } 16 \\
\text { artigos }\end{array}$ \\
\hline
\end{tabular}

Fonte: pesquisa direta em Base de Dados, 2020.

No Quadro 3, no que concerne as categorias temáticas, em Perfil do enfermeiro empreendedor, foram associadas às características, atitudes ou competências do enfermeiro. Assim como em Motivos e aspirações que levam o enfermeiro ao empreendedorismo de negócios, revela os motivos e oportunidades que estimulam o enfermeiro a empreender.

Em ralação ao Campo de atuação e variedade de negócios, fica evidente que existem vários nichos de mercado que possibilita o empreendedorismo na enfermagem, observados na maioria dos estudos. As Dificuldades e limitações ao empreendedorismo de negócios na Enfermagem englobam os obstáculos e barreiras enfrentados pelos profissionais da área, Já no que se refere ao Empreendedorismo na formação acadêmica, este se demonstra ausente, necessitando de maior atenção para a formação de enfermeiros liberais, sendo objeto de estudo de 4 pesquisas e mencionado nos demais estudos. 


\section{Discussão}

A resolução COFEN nº 0568/2018, regulamenta o funcionamento dos consultórios e clínicas de enfermagem, que oferecem serviços e/ou consultas de enfermagem, devendo estar adequadamente registrada como empresa nos Conselhos Regionais de Enfermagem, sendo isenta de pagamento de anuidades, porém, obriga o profissional a estar de acordo com sua situação financeira e cadastral. Sendo uma nova possibilidade de atuação do enfermeiro no mercado de trabalho (Cofen, 2018).

O empreendedorismo de negócios oferta aos profissionais enfermeiros oportunidades e possibilidades de autoemprego utilizando abordagens inovadoras. Dentre os motivos que influenciam a prática privada ou criação de negócio ao invés do emprego tradicional da assistência de enfermagem em hospitais, se encontra a percepção negativa nesses ambientes institucionais evidenciadas pelos turnos de trabalho, ambiente estressor disfuncional, falta de autonomia, sobrecarga de trabalho, modelo medico-centrado, além de baixos salários (Colichi et al., 2019).

Foram identificados na literatura dois aspectos motivacionais para instituir um negócio: a oportunidade e a necessidade. A oportunidade advém da identificação de uma ocasião favorável de empreendimento e a necessidade pela ausência de opções, pela insatisfação no mercado. A permuta da segurança do emprego habitual por responsabilizar-se pelos riscos de empreender seu próprio negócio resulta na mudança na conduta profissional pela aspiração de novos desafios (Morais et al., 2013).

A enfermagem possui inúmeros argumentos, oportunidades e possibilidades para ter seu empreendimento específico. A princípio, por se tratar de uma profissão que tem um entendimento das carências do homem de forma holística, integral e contextualizada. Segundo, devido ao potencial, criatividade e capacidade para explorar novas zonas sociais. E ainda, o incentivo ao empreendedorismo é de implacável relevância por proporcionar a obtenção de novos campos e estimular o desenvolvimento econômico e social do país (Andrade, Bem \& Sanna, 2015).

Dentre os motivos e aspirações que levam o enfermeiro ao empreendedorismo de negócios, não optando pelo trabalho institucional com arranjos tradicionais dos serviços de enfermagem em clínicas e hospitais, foram identificados na literatura ambientes organizacionais estressores, turnos, sobrecarga de trabalho, baixos salários oferecidos à 
categoria nos serviços privados, desgaste emocional por trabalhar muito tempo como empregado, modelo médico-centrado, ausência de autonomia, os enfermeiros investigados sentem-se limitados, necessitam seguir suas metas, fazer o diferencial em suas práticas, buscam flexibilidade nos horários de trabalho e geração de renda. Além disso, vislumbra possibilidade de lucratividade e independência, autonomia, estar no comando, ser seu próprio chefe, possuir controle de carreira, ser bem sucedido e busca pela satisfação profissional (Morais et al., 2013; Chagas et al., 2018; Colichi \& Lima, 2018).

Ainda em concordância, Copelli, Erdmann e Santos (2019), evidencia que a oportunidade para a enfermagem, caracteriza-se com a exploração de novos campos de ação profissional, ocasionando benefícios para a sociedade e pelo desfrute de circunstancias incomuns na práxis profissional que ocasionará melhoria na assistência, educação, nos negócios, sociedade ou em qualquer conjuntura de exercício do enfermeiro.

Nesta perspectiva, o profissional contemporâneo de enfermagem precisa estar em alerta ao panorama do trabalho na atualidade, investigando as particularidades e imposições do comércio equiparado à sua função social. A inovação contínua é exigida dos enfermeiros no contexto atual, considerando a orientação do mercado, que está cada vez mais disputado, despontando a autoestima como relevante componente para o exercício profissional pertinente (Araújo \& Nunes, 2018).

Avalia-se que, para ser empreendedor, são fundamentais competências como iniciativa, autonomia, empenho, motivação, entusiasmo, autoconfiança, imaginação, responsabilidade, raciocínio lógico, multifuncionalidade, persistência, esforço, disponibilidade e comprometimento, e que o progresso dessas atitudes completa a capacidade do empreendedorismo. Faz-se obrigatório, primeiramente, que o profissional enfermeiro se valorize e reconheça a importância da sua profissão para que seja capaz de convencer os clientes sobre a importância do seu negócio, por meio de comportamentos primordiais, mas, essencialmente, pela autoconfiança, responsabilidade e muito empenho (Dehghanzadeh et al., 2016; Tossin et al., 2017; Araújo \& Nunes, 2018; Lima et al., 2019).

Conforme Colichi e Lima (2018), determinadas características de um empreendedor são assumidas como as mesmas intrínsecas a um bom profissional enfermeiro. Em concordância, o estudo de Copelli et al. (2019) traz que a concepção de empreendedorismo na enfermagem está relacionada a uma agregação de características e habilidades encontradas neste profissional, desta forma, o enfermeiro empreendedor conceitua-se como aquele que 
dispõe de senso de oportunidade, independência, autonomia, inovação, flexibilidade, comunicação, que opera de forma holística, domina cenários novos de atuação direcionados ao cuidado, valoriza a profissão perante a sociedade, impulsionando o desenvolvimento econômico do país.

Em seu estudo quantitativo que objetivou identificar tendências empreendedoras dos enfermeiros de um hospital universitário, Costa et al. (2013), evidenciou que a faixa etária entre 27 e 33 anos apresentaram superior tendência empreendedora. Nos enfermeiros na faixa etária de 43 até 56 anos, com tempo superior de trabalho e com mais de 17 anos de formação, houve declínio da tendência empreendedora. Tais achados corroboram com os resultados de Chagas et al. (2018), que em sua pesquisa em um município mineiro, com 10 enfermeiros empreendedores, destacou que em relação ao perfil dos enfermeiros entrevistados, $70 \%$ eram do sexo feminino, predominando a faixa etária entre 30 a 40 anos.

Em uma amostra intencional por convite a 11 enfermeiros com empreendimentos na área da saúde no estado do Paraná, Morais et al. (2013), também determina em seus resultados uma população prevalentemente feminina, jovem com experiências profissionais variadas. Ficando evidente que atitudes empreendedoras estão relacionadas a enfermeiros jovens e com reduzido tempo de trabalho.

Ainda conforme Chagas et al. (2018), a alta lucratividade mensal desses enfermeiros empreendedores é ressaltada, variando entre $\mathrm{R} \$ 1.800,00$ a $\mathrm{R} \$ 85.000$. No tocante às características comportamentais dos empreendedores, constata-se que o comprometimento, estabelecimento de metas e independência e autoconfiança foram às características que alcançaram maiores médias. Entretanto, todas as características do estudo superaram a média mínima proposta, evidenciando que esses enfermeiros possuem elevada tendência empreendedora. Estudo realizado com 116 enfermeiras com o objetivo de identificar as características empreendedoras de enfermeiras, realizado em um hospital universitário, um hospital filantrópico e na Secretaria de saúde, aponta pontuação abaixo da média nos tópicos: autonomia, independência, necessidade de realização, riscos calculados e tendência criativa (Carvalho et al., 2016).

Segundo estudo de Silva et al. (2019), com 6 (seis) enfermeiros profissionais liberais, aponta força de vontade, competência, busca por conhecimento e exploração do campo de trabalho, como atributos necessários para o empreendedorismo. Conforme Ferreira et al. (2013), para os 15 acadêmicos de enfermagem que formava sua pesquisa, é preciso senso de 
(CC BY 4.0) | ISSN 2525-3409 | DOI: http://dx.doi.org/10.33448/rsd-v9i7.4442

oportunidade, atenção ao que ocorre ao seu redor, busca por oportunidades inovadoras, usufruir de circunstâncias atípicas em sua prática e sondar oportunidades não exploradas que sinalizem uma postura empreendedora.

Diferentes autores, identificaram a ampliação do campo de atuação da enfermagem empreendedora, detectando os seguintes negócios: terapias alternativas; estética, como depilação a laser e aplicação de cosméticos; aluguel de equipamentos; fabricação de produtos; podologia; atividades de assessoria, consultoria e gestão de projetos; instituto de repouso, moradia temporária e permanente para idosos; clínica de assistência domiciliar; educação; saúde ocupacional; transporte de pacientes; pesquisa; serviços que ofertam treinamentos, cursos preparatórios e de aperfeiçoamento profissional; comercio e marketing de produtos; cuidados de crianças e adolescentes; desenvolvimento de software; e clinicas privada (Morais et al., 2013; Andrade et al., 2015; Colichi et al., 2019).

No entanto, há também muitas dificuldades para os enfermeiros que adentram o meio empresarial. Geralmente, o início na área de negócios acontece sem a desvinculação completa da ocupação oficial, originando dupla ou tripla jornada de trabalho (Copelli et al., 2019).

De acordo com o estudo de Chagas et al. (2018) a dificuldade financeira é vista como obstáculo, algo que precisa ser encarado, pois a sobrevivência e progresso no mercado são efeitos de uma correta infraestrutura financiada, o que é, portanto, primordial para um fornecimento de cuidados de alta qualidade. Dentre outras dificuldades relata-se também o exagero de burocracia, carência de fiscalização e desconhecimento dos órgãos competentes, e apresentam fragilidades na normatização do mercado pelas instâncias encarregadas.

Destacam-se como as dificuldades encontradas no método de empreender, a rejeição e o preconceito por alguns profissionais de saúde, dificuldades financeiras, privação de preparo na graduação para empreenderem, ausência de conhecimentos de noções de contabilidade, questões legais e regulatórias que engloba carência de entendimento de legislação e processos burocráticos para licenciamento, gestão e registro de acordos privados, concorrência desleal, vinculada a escassez de credibilidade e insipiência da população a respeito das possibilidades de atuação do enfermeiro foram apontados como barreiras nas atividades dos enfermeiros empreendedores (Morais et al., 2013; Chagas et al., 2018; Colichi \& Lima, 2018; Silva et al., 2019). 
Além disso, é indicada ainda a prestação de serviços por profissionais não qualificados, sem graduação, particularmente em serviços homecare, de que oferecem trabalhos com preços inferiores, na maioria das vezes de maneira ilegal, já que não existe fiscalização, dificultando e desvalorizando a práxis do enfermeiro empreendedor (Colichi \& Lima, 2018).

Em sua pesquisa de abordagem qualitativa, Chagas et al. (2018) observou que é comum que tenha desafios e barreiras para iniciativas de empreendedorismo por enfermeiros. Contudo, apesar das dificuldades denotadas, os enfermeiros referiram satisfação pessoal e profissional baseados em seus empreendimentos, bem como já pensam nas possibilidades de ampliações e metas futuras.

Na totalidade dos estudos que compõe essa revisão havia o mesmo consenso: a ausência de disciplina de empreendedorismo e incentivo no decorrer da graduação para desenvolvimento da prática de empreender. De acordo com Roncon e Munhoz (2009), em sua pesquisa de Tendência Empreendedora Geral com 41 estudantes concluintes da graduação de enfermagem, demonstrou que tais estudantes possuíam baixas tendências empreendedoras, evidenciando atitude desmotivadora diante de um mercado de trabalho crescentemente competitivo.

Um estudo com 13 enfermeiras empreendedoras de várias províncias Iranianas, determinou que o conhecimento prévio auxilia positivamente na identificação de oportunidades adequadas. Em vista disto, o empreendedorismo precisa ser estimulado na formação acadêmica devido a sua significativa influência no crescimento econômico e social do país e da própria profissão de enfermagem (Jahanil et al., 2020).

\section{Considerações Finais}

Evidencia-se que a prática profissional na Enfermagem vai além da assistência hospitalar e docência, o empreendedorismo empresarial surge como uma inovadora área de atuação do enfermeiro no mercado de trabalho, possibilitando independência e autonomia profissional. São inúmeras as oportunidades e possibilidades de negócios na área da enfermagem, assim como as motivações e aspirações que conduzem os enfermeiros ao empreendedorismo. 
O empreendedorismo, como área de atuação inovadora na enfermagem, atua promovendo saúde a sociedade, através de seus consultórios, consultorias e auditorias. O empreendedorismo é significativo para movimentação e renovação da economia, proporciona melhorias na sociedade através da inovação, geração de empregos e expandindo as opções para os consumidores, com isso, reduzindo as inconsistências resultantes da crise.

A enfermagem possui inúmeros argumentos, oportunidades e possibilidades para ter seu empreendimento específico, tendo um amplo campo de atuação, além de possuir características e habilidades consideradas fundamentais para o empreendedorismo, como ter uma visão holística das necessidades humanas, dominar novos cenários e ter senso de oportunidade. Vários são os motivos que levam o enfermeiro ao empreendedorismo de negócios, não optando pelo trabalho institucional com arranjos tradicionais dos serviços de enfermagem sendo eles: ambientes organizacionais estressores, turnos, sobrecarga de trabalho e baixos salários, além de aspirarem por autonomia profissional. No entanto, há também muitas dificuldades para os enfermeiros que adentram o meio empresarial, mas a satisfação pessoal e profissional baseados em seus empreendimentos se sobressai.

Espera-se que este estudo sirva de guia para outros profissionais que cogitam conhecer a respeito do empreendedorismo, além do desenvolvimento de concepções que estimulem os estudantes e profissionais da área de enfermagem a potencializar, aprimorar, e fortalecer ações empreendedoras como alternativa de crescimento profissional, devendo o empreendedorismo ser fomentado na graduação, para o desenvolvimento da autonomia profissional e atitudes criativas e transformadoras, manifestadas nas variadas dimensões na práxis da enfermagem.

\section{Referências}

Andrade, A. C., Lima, S., Dal Ben, L. W., \& Sanna, M. C. (2015). Empreendedorismo na enfermagem: panorama das empresas no estado de são paulo de 1990 a 2010 . Revista Brasileira de Enfermagem, 68(1).

Araújo, M. R. A., \& Nunes, E. C. D. A. (2018). Empreendedorismo em enfermagem: um caminho promissor à luz da teoria de horta. Revista Saúde, 12. 
Carvalho, D. P., Vaghetti, H. H., Dias, J. S., \& Rocha, L. P. (2016). Características empreendedoras de enfermeiras: um estudo no sul do Brasil. Revista Baiana de Enfermagem, 30(4).

Chagas, S. C., Milagres, P. N., Silva, M. C. R., Cavalcante, R. B., de Oliveira, P. P., \& dos Santos, R. C. (2018). O empreendedorismo de negócios entre enfermeiros [Business entrepreneurship among nurses][El emprendimiento de negocios entre enfermeros]. Revista Enfermagem UERJ, 26, 31469.

Chiavenato, I. (2007). Empreendedorismo: dando asas ao espírito empreendedor: empreendedorismo e viabilidade de novas empresas. (2. ed.). São Paulo: Saraiva.

Conselho Federal de Enfermagem-Cofen (2018) Resolução nº 0568, de 2018. Regulamento dos consultórios e centros de enfermagem. Diário Oficial, Brasília, DF. Acesso em 20 de março de 2020, em http://www.cofen.gov.br/resolucao-cofen-no-0568-2018_60473.html.

Colichi, R. M. B., Bonini, B., Bueno, A., \& Lima, S. A. M. (2019). Empreendedorismo de negócios e Enfermagem: revisão integrativa. Revista Brasileira de Enfermagem, 72.

Colichi, R. M. B., \& Lima, S. A. M. (2018). Empreendedorismo na enfermagem: comparação com outras profissões da saúde. Revista Eletrônica de Enfermagem, 20.

Copelli, F. H. S., Erdmann, A. L., \& Santos, J. L. G. (2019). Empreendedorismo na Enfermagem: revisão integrativa da literatura. Revista Brasileira de Enfermagem, 72.

Costa, F. G., Vaghetti, H. H., Martinello, D. F. G., Mendes, D. P., Terra, A. C., Alvarez, S. Q., \& Lemos, L. A. P. (2013). Tendências empreendedoras dos enfermeiros de um hospital universitário. Revista Gaúcha de Enfermagem, 34(3), 147-154.

Dehghanzadeh, M. R., Kholasehzadeh, G., Birjandi, M., Antikchi, E., Sobhan, M. R., \& Neamatzadeh, H. (2016). Entrepreneurship psychological characteristics of nurses. Acta Medica Iranica, 595-599. 
Ferreira, G. E., Rozendo, C. A., dos Santos, R. M., Pinto, E. A., Costa, A. C. S., \& Porto, A. R. (2013). Características empreendedoras do futuro enfermeiro. Cogitare Enfermagem, 18(4).

Jahani, S., Abedi, H., Khoshknab, M. F., \& Elahi, N. (2020). The experience of Iranian entrepreneurial nurses on the identification of entrepreneurial opportunities: A qualitative study. Journal of family medicine and primary care, 7(1), 230.

Lima, K. F. R., Pinheiro, A. S., Silva, P. L. D., Cavalini, A. F. M., Bispo, A. D. S., Andrade, A. D. C., \& Medeiros, J. S. D. (2019). Perfil empreendedor do enfermeiro: contribuição da formação acadêmica. Rev. enferm. UFPE on line, 904-914.

Machado M. H. et al. (2019). (Coord.). Pesquisa Perfil da Enfermagem no Brasil. Relatório final. Rio de Janeiro: Fiocruz; Cofen, 2016. s.d. Acesso em 20 de março de 2019, em http://www.cofen.gov.br/perfilenfermagem/index.html.

Mendes, K. D. S., Silveira, R. C. C. P., \& Galvão, C. M. (2008). Integrative literature review: a research method to incorporate evidence in health care and nursing. Texto contexto enferm, 17(4), 758-64.

Morais, J. A., Haddad, M. D. C. L., Rossaneis, M. A., \& Silva, L. G. D. C. (2013). Práticas de enfermagem empreendedoras e autônomas. Cogitare Enfermagem, 18(4), 695-701.

Ronconi, P. F. R. E., \& Munhozi, S. (2009). Estudantes de enfermagem têm perfil empreendedor? Revista Brasileira de Enfermagem, 62.

Silva, E. K. B., Silva Junior, J. N. O., Neto, N. M. G., da Costa, L. S., Rodrigues, K. F., \& Alexandre, A. C. S. (2019). Arte e ciência do cuidar: alteridade, estabelecidos e outsiders na autonomia do enfermeiro como profissional liberal. Revista de Pesquisa: Cuidado é Fundamental, 370-376.

Tossin, C. B., Silva, L. G. D. C., Rossaneis, M. Â., \& Haddad, M. D. C. F. L. (2017). Perfil empreendedor de docentes do curso de enfermagem de uma universidade pública [Enterprising profile of teachers of the nursing course at a public university][Perfil 
emprendedor de los profesores del curso de enfermería de una universidad pública]. Revista Enfermagem UERJ, 25, 22233. ]

Whittemore, R., \& Knafl, K. (2005). The integrative review: updated methodology. Journal of advanced nursing, 52(5), 546-553.

\section{Porcentagem de contribuição de cada autor no manuscrito}

Grace Kelly Lima da Fonseca - 40\%

Clícia Lopes de Araújo - 30\%

Dean Douglas Ferreira de Olivindo - 30\% 